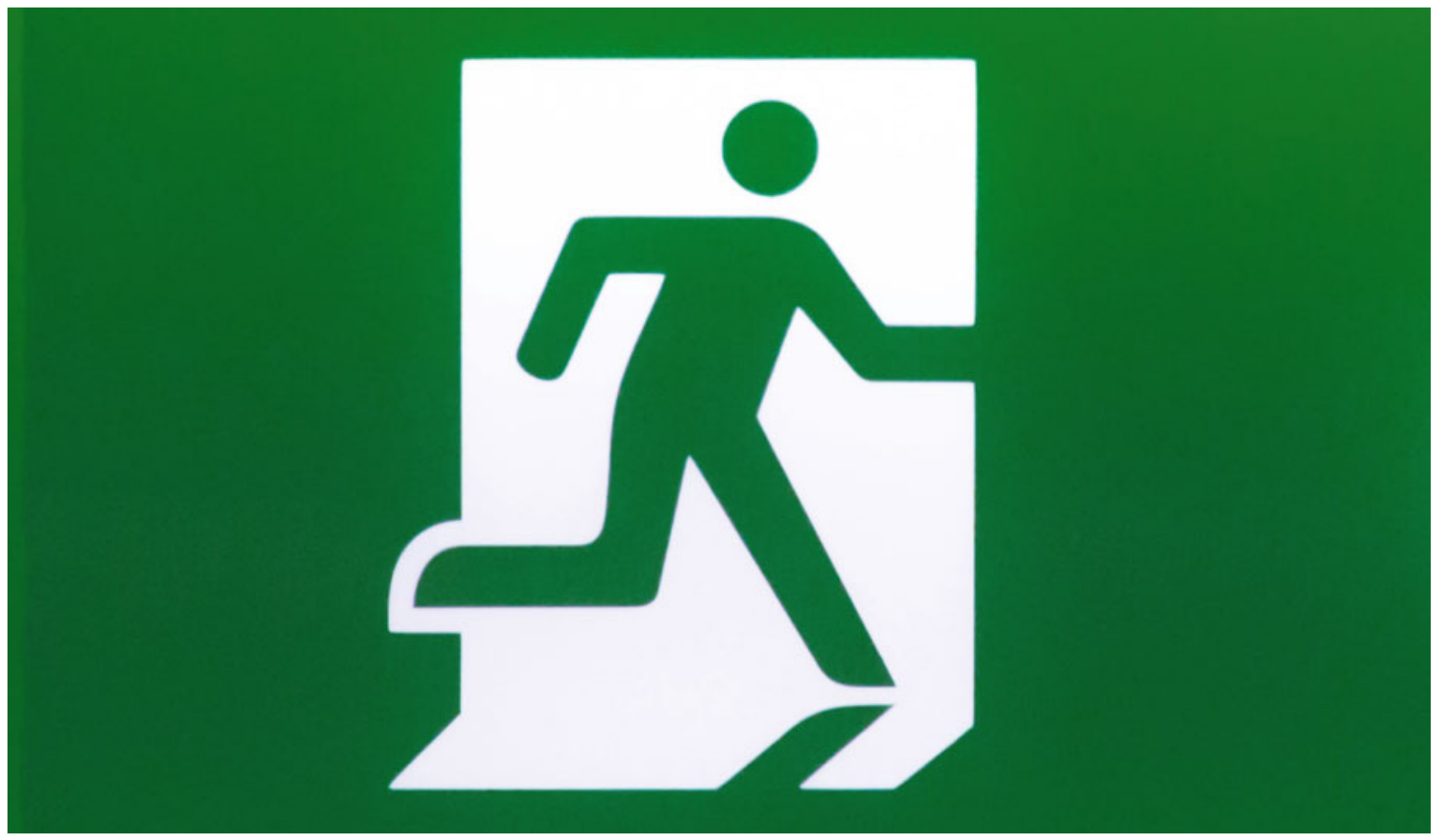

\title{
Vom Totmachen und vom Sterben
}

\section{Daniel Oertle}

Dr. med., Hausarzt in Zürich

Schauen Sie eigentlich Regional-Fernsehen? Nein? Sollten Sie aber. Sie verpassen sonst die fast wichtigsten Dinge, die es zu wissen gilt. Vor allem die Werbespots, die müssen Sie sich ansehen. Da sah man kürzlich eine ältere Frau, die früher mal eine bekannte Person des öffentlichen Lebens gewesen sein musste, denn so trat sie auf: sie sass am geöffneten Piano, im Hintergrund viele sicher gescheite Bücher, und sie sagte mit herrischer Stimme etwas von selbstbestimmtem Leben usw. und dass sie deshalb einer Totmach-Agentur beigetreten sei, weil sie nicht nur selbstbestimmt leben, sondern ebenso auch sterben wolle. Die ältere Frau sah im übrigen gar nicht sterbenskrank oder lebensmüde aus, nur eben herrisch. Den Tod wolle sie gefälligst

\section{Den Tod wolle sie gefälligst haben wann sie es wolle. Punkt.}

haben wann sie es wolle. Punkt. Jetzt Klaviermusik und das Logo der Totmach-Firma. Im nächsten Werbespot war von sinnlichen Begegnungen die Rede. Ob die Totmach-Firma und das erotische Dating-Portal ihre
Werbespots absichtlich hintereinander schalten liessen? Diese Werbung sehen Sie jedenfalls nur im Regional-Fernsehen.

Ein paar Tage später sahen wir die ältere Frau aus der Totmach-Werbung im Konzert. Meine Frau erkannte sie und wollte sich keinesfalls neben sie setzen: wer konnte schon wissen, ob sie nicht gerade heute ihr Date mit dem Tod hätte?

So ist es also: wer selbstbestimmt leben will soll gefälligst auch selbstbestimmt sterben. Und zwar - um Kosten zu sparen - gefälligst nicht zu spät: wir wissen, dass die Kosten, die Krankenkassen für die Versicherten aufwenden, im letzten Lebensjahr stark ansteigen Gelänge es nun dank Totmach-Firmen das Leben um dieses letzte Jahr zu verkürzen, entfielen riesige Kosten, die Krankenkassen wären saniert, die Prämien könnten gesenkt werden.

In Zukunft könnte ein am Handgelenk zu tragendes Wearable die wichtigsten Altersparameter aufzeichnen: Schrittlänge, Schlafdauer, Herzrhythmus-Störungen, Depressionsmerkmale und Sturzhäufigkeit. Diese Parameter würden online an das Centre of Death 
Control (CDC) übermittelt, wo ein Algorithmus den optimalen Zeitpunkt für das forcierte Ableben ermittelte. (Die Krankenkassen könnten die Kosten für das Wearable übernehmen.)

Es wird gemunkelt, dass die Totmach-Firma an die Börse gehen will. Also muss das Image des Totmachens aufgepeppt werden: Ein neues Logo mit sanftem Schwung, ganz in Blau, und ein paar bekannte Persönlichkeiten, die Werbung für die Firma machen. Die Totmach-Firma bietet neu Seminare für korrektes Sterben an: Sie hilft die letzte Steuererklärung auszufüllen, das Testament zu bereinigen, auf Facebook ein Kondolenzbuch zu eröffnen und Ordnung in die Fotodateien zu bringen. Pet und Glas sollen vorher sortiert und das Altpapier gebündelt werden.

Im Sterbefall garantiert die Totmach-Firma den perfekten Service. Sie holt die Sterbewilligen zu Hause ab, chauffiert sie in einer Limousine in ein diskretes Geschäftshaus im Industriequartier, das Sterbezimmer ist nett möbliert, es gibt einen Welcome-Apéro für alle Beteiligten, der Fotograf ist da für ein letztes Gruppenbild, das Glas mit dem hundertfach überdosierten Barbiturat ist reich verziert, es gibt Musik zum Getränk (beliebt sind Mozart, Vivaldi, Udo Jürgens). Die Tot-

\section{Die Totmach-Firma bietet neu Seminare für korrektes Sterben an.}

gemachten können anschliessend in einen der bereitstehenden Särge verschiedener Preiskategorien gelegt, mit dem Lift in die Tiefgarage und im neutralen Lieferwagen weggeführt werden. Alles zum Fixpreis, der im Expressfall verdoppelt wird.

Wie langweilig gewöhnlich ist dagegen das Sterben (wenn es nicht unerwartet und über Nacht geschieht dann spricht man von einem "guten Tod»). Das bedächtige Dahinsterben, das Langsam-immer-weniger-
Werden: das passt so gar nicht in unsere effiziente Welt. Sterben ist doch ein soziales Geschehen, das uns Zeit lässt, sich vielleicht noch an ein paar wunderbare Dinge zu erinnern, Tage mit den Kindern, an einen klaren Morgen auf einer Bergtour, an ein langsam ausklingendes Fest mit Freunden. Gelassen sterben in einer respektvollen Umgebung, begleitet von unaufge-

\section{Sterben ist immer elend, todtraurig. Sterben ist eine Zumutung.}

regten Pflegenden und dem langjährigen Hausarzt, der mit Morphium nicht geizt. Vielleicht kann noch etwas ausgesprochen werden, vielleicht kommt noch jemand unerwartet zu Besuch und begleitet den Sterbenden in den Garten, es ist ein lauer Abend, irgendwo lärmen Kinder und Mauersegler sind in der Luft.

Sterben ist immer elend, todtraurig. Sterben ist für alle eine Zumutung. Und nach dem Tod bleibt den Zurückgebliebenen die Leere, die Trauer. Aber nach dem assistierten Suizid, dem Totmachen, kommen zur Leere und Trauer noch die Scham, die Zweifel, die Selbstvorwürfe: Hätte dieses Sterben nicht verhindert werden können? War es nicht zu früh? Haben wir den Sterbewilligen nicht genügend unterstützt, begleitet, getragen?

Vielleicht hat die ältere Frau im Regionalfernsehen dies alles nicht bedacht, als sie ihr Gesicht für den Werbespot hergab: Der Totmach-Kult übt auf Alte und Sterbende zunehmend Druck aus, sich doch gefälligst nicht so zu zieren mit dem Sterben, es ist ja alles so sauber und einfach, lieber heute als morgen, auch aus Kostengründen.

Bildnachweis

(c) Tuthelens | Dreamstime.com 